\title{
Efficient DNA release from PAMAM dendrimer- modified superparamagnetic nanoparticles for DNA recovery
}

\author{
Atsushi Arakaki ${ }^{1}$, Keiyu Shibata ${ }^{1}$, Takeyuki Mogi ${ }^{2}$, Masahito Hosokawa ${ }^{1}$, Keiichi Hatakeyama ${ }^{1}$, \\ Hideyuki Gomyo ${ }^{1}$, Tomoyuki Taguchi ${ }^{2}$, Hitoshi Wake ${ }^{2}$, Takeo Tanaami ${ }^{2}$, Tadashi Matsunaga ${ }^{1}$ \\ and Tsuyoshi Tanaka ${ }^{1}$
}

DNA recovery using solid-phase extraction is a fundamental technique in molecular biology and biotechnology. Our research group developed a novel DNA recovery method using amine-modified magnetic nanoparticles (MNPs) as a solid support. The use of MNPs simplifies the DNA recovery processes and permits their use in automated systems. In this study, we prepared polyamidoamine-modified superparamagnetic particles (PAMAM-SpMNPs) with 10-nm magnetite cores and used them for DNA recovery. To improve the DNA-release efficiency, the surface amine numbers on the particles were evaluated to modify each generation of PAMAM. With this optimization, the PAMAM-SpMNPs maintained a high DNA adsorption capacity and high dispersivity in solution. As a result, the DNA release from the PAMAM-SpMNPs of every generation was highly efficient. In particular, the release of DNA from the G4 to G6 PAMAM-SpMNPs was greater than 95\%. Furthermore, an alternating magnetic field (AMF) was applied to expedite the DNA release from the PAMAM-SpMNPs. Complete DNA release was achieved using AMF treatment for $10 \mathrm{~min}$. The DNA recovery method using the PAMAM-SpMNPs will permit various types of testing using DNA from a low volume sample, such as in a micro total analytical system.

Polymer Journal (2012) 44, 672-677; doi:10.1038/pj.2012.32; published online 4 April 2012

Keywords: alternating magnetic field; DNA extraction; DNA release; magnetic nanoparticles; PAMAM dendrimer

\section{INTRODUCTION}

DNA recovery is an important process for biological tests based on nucleic acid sequences such as bacterial detection, virus genotyping, and gene diagnosis. A typical DNA recovery process uses solid-phase extraction. In particular, a technique developed by Boom et al. ${ }^{1}$ using silica particles has been applied to various commercially available DNA extraction kits. This method consists of several processes, including removing hydrated water from a DNA molecule using highly concentrated chaotropic reagents, inducing DNA adsorption to the silica particles, washing with an organic solvent, and drying the particles, thus making the protocol complicated. In addition, the method uses chaotropic reagents and organic solvents, which may inhibit downstream applications requiring enzymatic reactions (for example, PCR amplification, gene cloning, digestion, and sequencing).

Magnetic nanoparticles (MNPs) are an ideal material for use in automated separation processes because they can be conveniently collected by a magnet. They have been used in various biotechnological applications, including cell separation, ${ }^{2-4}$ immunoassays, ${ }^{5-7}$ DNA detection, ${ }^{8-12}$ and DNA recovery. ${ }^{13-18}$ We have developed various types of amine-modified MNPs and have applied them to automated DNA recovery. ${ }^{13,15,18}$ This development was based on the electrostatic interactions between the amino groups on the MNPs and the phosphate groups from nucleic acids. ${ }^{19}$ The method consists of several consecutive processes, including DNA adsorption, washing, and release, although it does not require any chaotropic reagents or organic solvents. This method is especially applicable to DNA extraction from plant cells, which cannot be achieved using the Boom method because the addition of chaotropic agents increases the solution viscosity owing to aggregation of the proteoglycans. ${ }^{18}$

The DNA binding capability of amine-modified MNPs was significantly improved by modifying them with polyamidoamine (PAMAM) dendrons. ${ }^{16}$ The high amine density increased the DNA adsorption capacity of the PAMAM-modified MNPs (PAMAMMNPs). In addition, the dispersivity of the MNPs in a solution was increased with the high amino density, generating a repulsive force among the PAMAM-MNPs. However, the highest DNA-release ratio was approximately $80 \%$ of the total DNA captured onto the PAMAM-MNPs. The remaining 20\% of the DNA molecules were tightly associated with the high-density amino groups on the solid surface by electrostatic interaction and could not be easily released from the surface. ${ }^{20}$ An improvement in the DNA-release efficiency is required for complete DNA recovery using PAMAM-MNPs.

${ }^{1}$ Division of Biotechnology and Life Science, Institute of Engineering, Tokyo University of Agriculture and Technology, Tokyo, Japan and ${ }^{2}$ Yokogawa Electric Corporation, Tokyo, Japan Correspondence: Professor T Tanaka, Division of Biotechnology and Life Science, Institute of Engineering, Tokyo University of Agriculture and Technology, 2-24-16, Naka-cho, Koganei, Tokyo, Japan.

E-mail: tsuyo@cc.tuat.ac.jp

Received 26 December 2011; revised 13 February 2012; accepted 14 February 2012; published online 4 April 2012 
In this study, we prepared polyamidoamine-modified superparamagnetic particles (PAMAM-SpMNPs) using 10-nm magnetite cores and used them for DNA recovery. To improve the DNA-release efficiency, we optimized the surface amine numbers of the PAMAMSpMNPs to control the interaction between a DNA molecule and the amine groups on the particle. Furthermore, an alternating magnetic field (AMF) was applied to expedite the DNA release from the PAMAM-SpMNPs. The DNA-release method using the PAMAMSpMNPs introduced in this study will contribute to DNA recovery from extremely small biological samples.

\section{EXPERIMENTAL PROCEDURE}

\section{Materials}

PAMAM dendrimers with cystamine cores (generations 1-6 (G1-G6 dendrimers)) were obtained from Sigma-Aldrich (St Louis, MO, USA). 3-[2-(2Aminoethylamino)-ethylamino]-propyltrimethoxysilane (AEEA) was obtained from Fluka Chemical (Buchs SG, Switzerland). $N$-(4-maleimidobutyryloxy) succinimide (GMBS) and dithiothreitol (DTT) were purchased from Wako Pure Chemical Industries (Osaka, Japan). Sulfo-succinimidyl 6-[3'(2-pyridyldithio)propionamido] hexanoate (Sulfo-LC-SPDP) was purchased from Pierce Chemical (Rockford, IL, USA). A Picogreen $\left(\lambda_{\mathrm{ex}}=502 \mathrm{~nm}, \lambda_{\mathrm{em}}=523 \mathrm{~nm}\right) \mathrm{dsDNA}$ assay kit was purchased from Invitrogen (Carlsbad, CA, USA). Superparamagnetic nanoparticles (SpMNPs) were purchased from the Ferrotec Corporation (Tokyo, Japan). The average diameters of the SpMNPs were $10 \mathrm{~nm}$, and these particles were used as solid supports for silanization. The other commercially available reagents were either of analytical or laboratory grade.

\section{Preparation of AEEA-modified SpMNPs (AEEA-SpMNPs)}

SpMNPs $(10 \mathrm{mg})$ were incubated with $20 \mathrm{ml}$ of $2 \%$ AEEA solution in EtOH at room temperature for $10 \mathrm{~min}$. After washing with dimethylformamide (DMF), the AEEA-SpMNPs were baked at $120^{\circ} \mathrm{C}$ in $20 \mathrm{ml}$ DMF for 30 min with sonication every $10 \mathrm{~min}$. After this treatment, the particles were washed with $\mathrm{MeOH}$ three times and stored in $\mathrm{MeOH}$ at $4{ }^{\circ} \mathrm{C}$. The concentration of the SpMNPs in suspension was determined by measuring the optical density of the solution at $660 \mathrm{~nm}$ using a spectrophotometer (ES-2; Malcom, Tokyo, Japan).

Surface modification of AEEA-SpMNPs with PAMAM dendrimers PAMAM-SpMNPs were synthesized using a convergent method. ${ }^{20}$ As a consequence of using this method, the density of the amino groups on the PAMAM-SpMNPs was easily controlled with high reproducibility. The method used is described briefly below. G1-G6 dendrimers (final concentration: $0.5 \mathrm{~mm}$ ) in $200 \mu \mathrm{l}$ of $\mathrm{MeOH}$ were mixed with $800 \mu \mathrm{l}$ of DTT (final concentration: $0.5 \mathrm{~mm}$ ) in a $10 \mathrm{~mm}$ phosphate buffer containing $140 \mathrm{mM} \mathrm{NaCl}$ (phosphate buffered saline; PBS, pH 7.4) to produce dendron-thiols. After stirring at room temperature for $12 \mathrm{~h}$, the dendron-thiol solution was diluted 10-fold with PBS buffer. Simultaneously, the AEEA-SpMNPs $(10 \mathrm{mg})$ were incubated with a $1 \mathrm{mM}$ GMBS solution in $20 \mathrm{ml}$ PBS for $1 \mathrm{~h}$ to introduce maleimide groups on their surface. After washing with PBS three times, the maleimide-functionalized SpMNPs (final concentration: $0.5 \mathrm{mg} \mathrm{ml}^{-1}$ ) were reacted with the dendron-thiol solution. The PAMAM-SpMNP suspension was incubated and sonicated at room temperature for $1 \mathrm{~h}$. After washing with $\mathrm{MeOH}$ three times, the PAMAM-SpMNPs were stored in $\mathrm{MeOH}$ at $4{ }^{\circ} \mathrm{C}$. The size distributions of the PAMAM-SpMNPs were evaluated using a laser particle analyzer (ELS-8000, Otsuka Electronics, Osaka, Japan), and the monodispersion of the PAMAM-SpMNPs was verified before use.

\section{Determination of surface amine numbers of PAMAM-SpMNPs}

To determine the number of amine moieties on their surfaces, PAMAMSpMNPs $(250 \mu \mathrm{g})$ were incubated in $10 \mathrm{~mm}$ Sulfo-LC-SPDP in PBS at room temperature for $30 \mathrm{~min}$. The Sulfo-LC-SPDP-conjugated MNPs were washed three times with PBS and incubated in $200 \mu \mathrm{l}$ of $20 \mathrm{~mm}$ DTT in PBS to release 2-pyridylthiol. The absorbance of 2-pyridylthiol at $343 \mathrm{~nm}$ was measured using a spectrophotometer. The concentration of the Sulfo-LC-SPDP that reacted with the primary amino groups on the SpMNPs was determined using a standard curve generated with different concentrations of Sulfo-LC-SPDP in $20 \mathrm{~mm}$ DTT.

\section{Measurement of zeta potentials of PAMAM-SpMNPs}

The zeta potential of the PAMAM-modified SpMNPs was analyzed using a laser particle analyzer (ELS-8000). The PAMAM-SpMNPs were diluted to $1 \mu \mathrm{g}^{-1} \mathrm{ml}$ using ultrapure water for measuring. The zeta potential was calculated from their electrophoretic mobilities.

\section{Recovery of $\lambda$ DNA using PAMAM-SpMNPs}

The DNA recovery scheme is presented in a simplistic form in Figure 1a. The PAMAM-modified SpMNPs $(10 \mu \mathrm{g})$ were mixed with appropriate amounts of lambda DNA ( $\lambda$ DNA) (Takara Bio, Shiga, Japan) in $40 \mu \mathrm{l}$ of $10 \mathrm{~mm}$ Tris-HCl buffer and incubated at room temperature. The DNA-SpMNP complexes were collected magnetically and washed three times with Tris- $\mathrm{HCl}$ buffer. The adsorbed DNA was quantified as the initial DNA amount minus the DNA amount in the supernatant after magnetic separation. To evaluate the DNA release behaviors, the $\lambda$ DNA-MNP complexes were dissolved with $1 \mathrm{M}$ phosphate buffer $(\mathrm{pH} 8.0)$ for $20 \mathrm{~min}$ at $80^{\circ} \mathrm{C}$. After magnetic separation, the supernatants were collected as DNA-released fractions. The amount of DNA was determined using the DNA intercalator, PicoGreen (excitation at $502 \mathrm{~nm}$, emission at $523 \mathrm{~nm}$ ). The fluorescent intensity was measured using a fluorescence microplate reader (FLUO Star Galaxy, BMG Lab Technologies Inc., Offenburg, Germany). Calibration curves for DNA quantification were prepared using $\lambda \mathrm{DNA}$ as a standard in appropriate buffers.

\section{DNA release from PAMAM-SpMNPs by applying an AMF}

A 3-kW induction heating power supply (EASYHEAT, Ameritherm Inc., Scottsville, NY, USA) was used with a remote heating station and custom-made coils. A 2-turn, 30-mm OD coil resonating at $248 \mathrm{kHz}$ was used. During the experiments, cooling water $\left(10-16^{\circ} \mathrm{C}\right)$ was circulated through the coil. To investigate the DNA release behaviors in the presence of an AMF, PAMAM-SpMNPs $(1 \mathrm{mg})$ were used to adsorb the $\lambda$ DNA or Cy3-labeled oligonucleotide. The DNA-PAMAM-SpMNPs complexes were dispersed in a $1 \mathrm{M}$ phosphate buffer $(\mathrm{pH}$ 8.0) and placed in a PCR microtube. The suspensions were subjected to AMF treatment for 1-10 min. After magnetic separation, the supernatants were collected as DNA-released fractions. The amount of DNA was determined using the DNA intercalator, PicoGreen. The fluorescent intensity was measured using a fluorescence microplate reader. Calibration curves for the DNA quantification were prepared using $\lambda \mathrm{DNA}$ or a Cy3-labeled oligonucleotide as a standard in appropriate buffers. The temperature changes in the suspensions containing PAMAM-SpMNPs were monitored using a thermometer (FL-2000, Anritsu Meter Co., Ltd., Tokyo, Japan) equipped with a fiber optic sensor (FS-100, Anritsu Meter Co., Ltd.).

\section{RESULTS}

Preparation and characterization of PAMAM-SpMNPs

The 10-nm SpMNPs were modified using 1-6 generations of PAMAM dendrimers. The PAMAM dendrimers were covalently bound to the SpMNPs of magnetite using AEEA and GMBS. The dendrimer modification was confirmed by measuring the surface amine numbers from the PAMAM-SpMNPs. The experimental and theoretical amine numbers of the PAMAM-SpMNPs in each generation are listed in Table 1. The experimental amine numbers of the PAMAM-SpMNPs increased from generations 1 through 6 . The amine number of the G6 PAMAM-MNPs $\left(5.2 \times 10^{2}\right.$ amino groups/ particle) was approximately four times that of the G1 PAMAMSpMNPs $\left(1.2 \times 10^{2}\right.$ amino groups/particle). The theoretical amine numbers were estimated for a PAMAM dendrimer that was tightly immobilized on the surface of a SpMNP, such as a 10-nm sphere with close hexagonal packing. On the basis of the repulsive force among the dendrons, the experimental amine numbers were lower than the theoretical amine numbers for each generation. The experimental amine number of the G6 PAMAM-SpMNPs divided by the surface area of a SpMNP yields a value of approximately 1.6 amino groups $\mathrm{nm}^{-2}$. The amino-group density of the 10-nm G6 PAMAM-SpMNPs was approximately $80 \%$ of that of the $80-\mathrm{nm}$ 


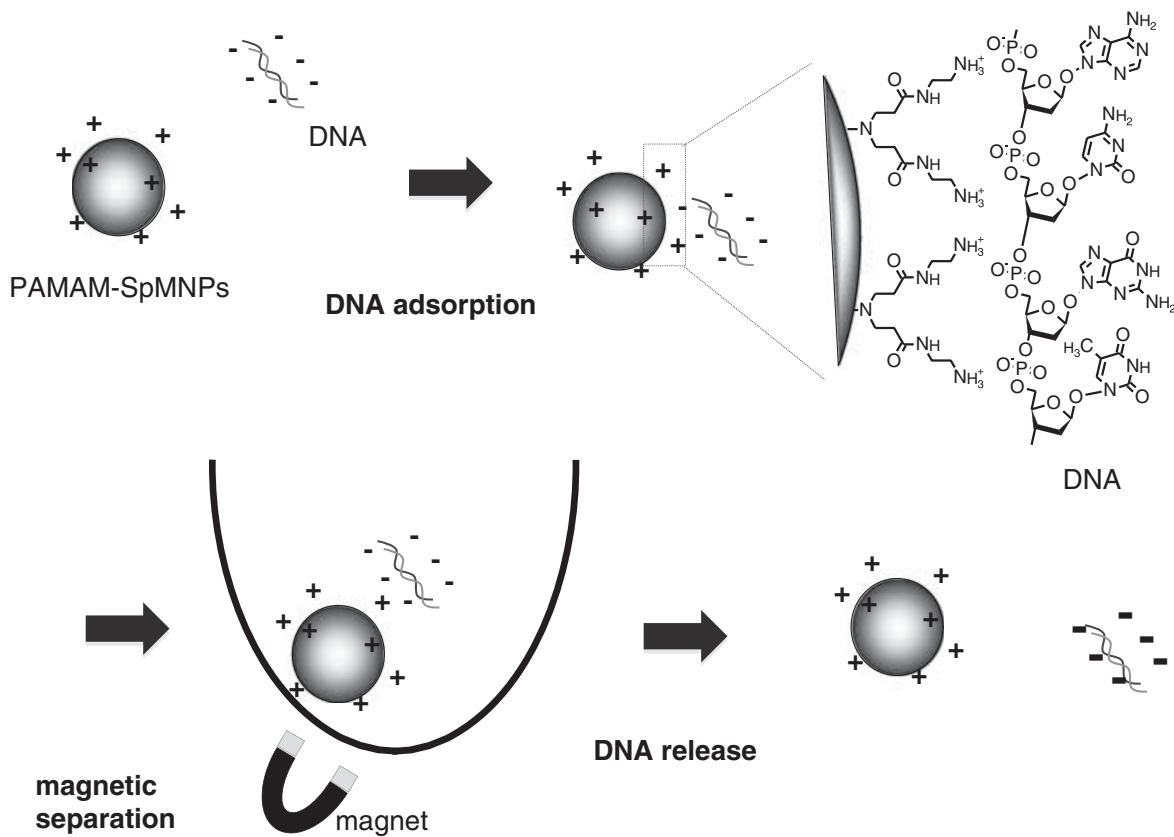

Figure 1 Scheme for DNA recovery using PAMAM-SpMNPs. DNA molecules were adsorbed onto the PAMAM-SpMNPs via electrostatic interactions. The DNA and PAMAM-SpMNP complexes were separated from the supernatant by an attracting magnetic force. After removal of the supernatant and washing of the PAMAM-SpMNPs, DNA was released from the PAMAM-SpMNPs in a phosphate buffer by heating the solution. Alternatively, an AMF was applied to expedite the DNA release from the PAMAM-SpMNPs.

Table 1 Amine numbers immobilized on PAMAM-SpMNPs

\begin{tabular}{|c|c|c|c|c|}
\hline $\begin{array}{l}\text { Diameter } \\
(\mathrm{nm})\end{array}$ & Generation & $\begin{array}{c}\text { Theoretical } \\
\text { amine } \\
\text { number/particle }\end{array}$ & $\begin{array}{c}\text { Experimental } \\
\text { amine } \\
\text { number/particle }\end{array}$ & $\begin{array}{c}\text { Experimental/ } \\
\text { theoretical } \\
\times 100(\%)\end{array}$ \\
\hline \multirow[t]{6}{*}{10} & G1 & 299 & $124 \pm 6$ & 41 \\
\hline & G2 & 345 & $246 \pm 17$ & 71 \\
\hline & G3 & 448 & $331 \pm 23$ & 74 \\
\hline & G4 & 573 & $348 \pm 28$ & 61 \\
\hline & G5 & 796 & $431 \pm 26$ & 54 \\
\hline & G6 & 1034 & $517 \pm 59$ & 50 \\
\hline
\end{tabular}

G6 PAMAM-MNPs prepared using the self-assembly dendronization method using thiol core, functionalized PAMAM dendrons.

The prepared PAMAM-SpMNPs exhibit a high dispersivity in solution, and the dispersivity increased with successive dendrimer generations. Figure 2 shows the suspensions of PAMAM-SpMNPs in PBS buffer ( $\mathrm{pH}$ 8.0) after sonication for $1 \mathrm{~h}$. The G1-G4 PAMAMSpMNPs settled out by aggregation, whereas the G5 and G6 PAMAM-SpMNPs remained dispersed in the solution. The $\xi$ potential of the PAMAM-SpMNPs in the successive generations was then measured (Table 2 ). The $\xi$ potential correlated with the amine number of the PAMAM-SpMNPs $\left(R^{2}=0.94\right)$, suggesting that the electrostatic interaction between the SpMNPs had a major role in the observed aggregations in the solution.

\section{DNA binding to and release from PAMAM-SpMNPs}

The DNA binding to and release from the PAMAM-SpMNPs were evaluated using $\lambda \mathrm{DNA}$ as a model sample. $\lambda \mathrm{DNA}$ was bound to the PAMAM-SpMNPs via electrostatic interactions between the phosphate groups from the DNA and the amino groups from the PAMAM dendrimers. After binding, the PAMAM-SpMNPs immediately

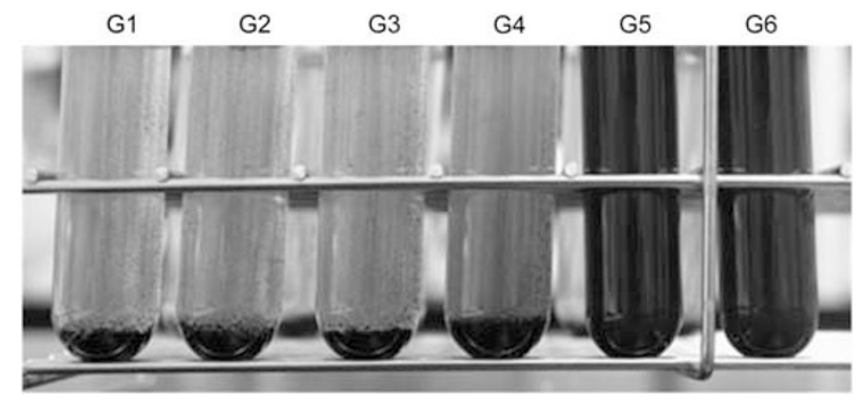

Figure 2 PAMAM-dendrons immobilized on SpMNPs in a PBS buffer. The SpMNPs were incubated for $1 \mathrm{~h}$ after dispersion by sonication.

Table $2 \zeta$ potentials of PAMAM-SpMNPs

\begin{tabular}{ll} 
Generation & $\zeta$ Potentials $(\mathrm{mV})$ \\
\hline G1 & $12.5 \pm 13.7$ \\
G2 & $26.5 \pm 11.7$ \\
G3 & $31.8 \pm 8.9$ \\
G4 & $37.0 \pm 16.7$ \\
G5 & $38.8 \pm 10.2$ \\
G6 & $43.0 \pm 8.1$
\end{tabular}

aggregated; the aggregation increased the net magnetization of the PAMAM-SpMNPs and facilitated their magnetic collection from solution. The DNA was then released by adding phosphate ions, which replaced the DNA bound to the PAMAM-SpMNPs, and heating at $80^{\circ} \mathrm{C}$ for $20 \mathrm{~min}$. The amounts of both the bound and released DNA using $10 \mu \mathrm{g}$ of PAMAM-SpMNPs increased with the successive dendrimer generations (Figure 3). The amount of DNA 
bound to the G6 PAMAM-SpMNPs (566 $\mu \mathrm{g} / 10 \mu \mathrm{g}$ SpMNPs) was 333\% of the amount bound to the G1 PAMAM-SpMNPs $(170 \mu \mathrm{g} / 10 \mu \mathrm{g}$ SpMNPs). The DNA release from the PAMAM-SpMNPs for all of the generations was highly efficient, especially for the G4-G6 PAMAMSpMNPs, which released greater than $95 \%$ of their DNA.

The DNA-binding capability of the PAMAM-SpMNPs was compared with that of PAMAM-MNPs prepared using $80-\mathrm{nm}$ magnetite cores, as previously reported. ${ }^{20} \mathrm{~A}$ binding experiment was performed using the same amount of particles under the same binding conditions. The resulting amount of DNA bound to the G6 PAMAM-SpMNPs was four times that bound to the G6 PAMAM-MNPs (Table 3). Moreover, the amine number of the G6 PAMAM-SpMNPs was six times larger than that of the G6 PAMAM-MNPs.

Enhancement of DNA release from PAMAM-SpMNPs by AMF MNPs subjected to an external AMF generate a remarkable heating effect because of their magnetic loss. ${ }^{21,22}$ Because the heat is generated from the MNP core, the energy should be directly transferred to the water and other molecules that exist locally on the MNP surface, resulting in the rapid and efficient heating of the target molecule. In this study, we used an AMF to enhance DNA release from the PAMAM-SpMNP surface.

Before the investigation, heat generation from bare MNPs was confirmed by applying an external AMF to a glass vessel containing MNPs dispersed in a phosphate buffer. When 80-nm ferromagnetic MNPs were added at a concentration of $250 \mu \mathrm{g} \mathrm{ml}^{-1}$, a rapid increase in

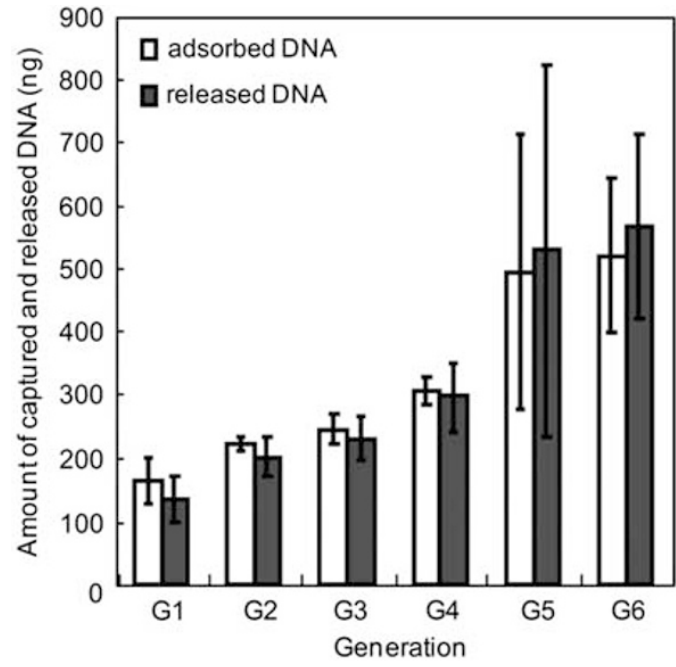

Figure 3 DNA amounts adsorbed on and released from the PAMAMSpMNPs as a function of dendrimer generation. The data are compiled from triplicate experiments and are expressed as \pm s.d.

Table 3 Amount of adsorbed DNA by G6 PAMAM-MNPs

\begin{tabular}{lcc}
\hline $\begin{array}{c}\text { Amine number } \\
\text { (amines per 10 } \mu \mathrm{g} \text {-MNPs) }\end{array}$ & $\begin{array}{c}\text { Amount of adsorbed DNA } \\
\text { (ng per 10 } \mu \mathrm{g}-M N P s)\end{array}$ \\
\hline $10 \mathrm{~nm}$ & $1.9 \times 10^{15}$ & 566 \\
$80 \mathrm{~nm}$ & $3.1 \times 10^{14}$ & 114 \\
\hline
\end{tabular}

Abbreviation: MNPs, magnetic nanoparticles. the solution temperature was observed within 1 min (Supplementary Figure 1). In contrast, a slow and small temperature change was observed when 10-nm SpMNPs were used at the same concentration, although the SpMNPs should have experienced a local temperature increase at the surface region (Figure 4). These behaviors conformed to the ferromagnetic and superparamagnetic characteristics derived from the $80-\mathrm{nm}$ and $10-\mathrm{nm}$ sizes of the magnetite particles.

The temperature changes in the solution containing SpMNPs were determined when different AMF power levels were applied to the SpMNPs. The Cy3-labeled oligonucleotide was bound to the PAMAM-SpMNPs, and an AMF was applied. The release of the oligonucleotide was monitored by measuring the fluorescent intensity of the solution. The time course of the oligonucleotide release indicated that it occurred within $1 \mathrm{~min}$ (Figure 4), whereas no temperature increase was observed over $10 \mathrm{~min}$. This result suggests that the heat generated from a SpMNP increases the local temperature at the surface and facilitates the release of the oligonucleotide from the surface.

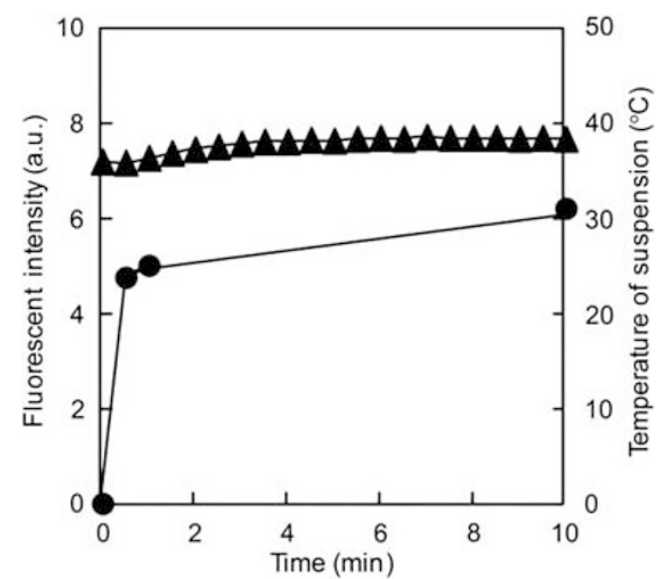

Figure 4 Fluorescent intensities of the Cy3-labeled oligonucleotide released from G6 PAMAM-SpMNPs by applying an AMF at $248 \mathrm{kHz}$. ๑ : Fluorescent intensity, $\boldsymbol{\Delta}$ : Temperature of suspension.

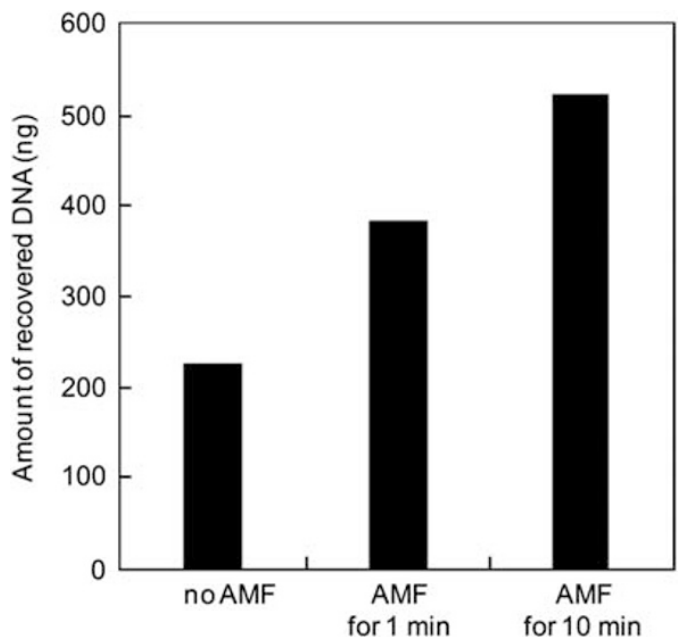

Figure 5 Amount of released lambda DNA from G6 PAMAM-SpMNPs by applying or not applying an AMF at $248 \mathrm{kHz}$. The particle suspensions were incubated for $20 \mathrm{~min}$ at room temperature. 
The DNA release from the G6 PAMAM-SpMNPs was investigated by applying an external AMF to the vessel. When no AMF was applied to a solution containing DNA bound to G6 PAMAMSpMNPs, approximately $40 \%$ (200 ng) of the DNA was released from the PAMAM-SpMNPs after $20 \mathrm{~min}$ of incubation in a phosphate buffer (Figure 5). When an AMF was applied for $1 \mathrm{~min}$ and $10 \mathrm{~min}$, approximately $80 \%(400 \mathrm{ng})$ and $100 \%(500 \mathrm{ng})$ of the DNA was released from the PAMAM-SpMNPs, respectively. Complete DNA release was achieved after AMF treatment for $10 \mathrm{~min}$. The heat generation of the SpMNPs was considered to support the rapid and highly efficient DNA release from the SpMNPs.

\section{DISCUSSION}

In a previous report, we developed a novel DNA recovery method based on electrostatic interactions between the phosphate groups of DNA and the amino groups on the solid support. ${ }^{16,19}$ The solid support first used nanoparticles that had been modified with an amino-silane monolayer. These particles had a low DNA adsorption capacity and low particle dispersivity, although the DNA release was efficient. ${ }^{17}$ The capacity of the amine-modified nanoparticle was then improved by covering it with PAMAM using divergent synthesis. ${ }^{15,16}$ However, the PAMAM-modified particles had two problems: controlling the amine numbers on the particles was difficult using the divergent method, and the DNA-release efficiency was low, with a high amino-group density for high dispersivity. We recently developed the self-assembly dendronization method using thiol core, functionalized PAMAM dendrons as a convenient method for PAMAM modification, which allowed the PAMAM-MNPs to be fabricated with sufficient reproducibility. ${ }^{20}$ In this study, to improve the DNA-release efficiency, the selfassembly dendronization method was used for the synthesis of PAMAM-modified particles. SpMNPs were used as a solid support, and two effects were expected. One effect was an improvement of the capacity for DNA adsorption to the particle because of the enlargement of the specific surface area per weight. The other expected effect was a lower interaction per particle between the amino groups on the particle and the phosphate groups in the DNA. These effects were capable of achieving a significant improvement of DNA-release efficiency from the PAMAM-modified particles.

The PAMAM-MNPs, which have a diameter of $80 \mathrm{~nm}$, require a high amino-group density for a high dispersivity and DNA adsorption capacity. However, a high amino-group density is not effective for DNA release. ${ }^{16}$ Thus, we used SpMNPs as a solid support for PAMAM modification. The average diameters of the SpMNPs were $10 \mathrm{~nm}$. Therefore, the magnetic agglomerations did not occur easily, and the specific surface area was larger than that of the 80-nm MNPs used in the previous study. The G6 PAMAM-SpMNPs, which had only $80 \%$ of the amine density of the previous $80-\mathrm{nm}$ PAMAMMNPs, exhibited high dispersivity. A superparamagnetic particle is not magnetic without an external magnetic field. Therefore, the G5 or G6 PAMAM-SpMNPs remained dispersed in a high salt concentration buffer (PBS) for $1 \mathrm{~h}$, despite having a lower repulsive force than the previous $80-\mathrm{nm}$ PAMAM-MNPs of the lower amino density. The PAMAM-SpMNPs that adsorbed DNA were able to collect easily and rapidly because of the cancelation of the electrostatic repulsive force among the particles by the DNA. Our proposed method offers the following benefits over conventional methods: reduced chemical requirements, ease of separation using a magnet and ease of automation, whereas conventional methods using a silica column require centrifugation, which is the most difficult step to automate. In addition, our method yielded a DNA recovery ratio of $95 \%$, which is high compared with the other methods. ${ }^{23,24}$
The DNA adsorbed on the G6 PAMAM-SpMNPs could be completely released from their surfaces. We considered the efficient release to be caused by the magnitude of the electrostatic interaction between the DNA and amine-modified particles. The numbers of amino groups and the amounts of adsorbed DNA on the SpMNPs (10-nm) and MNPs (80-nm) are summarized in Table 3. The particle numbers in $10 \mu \mathrm{g}$ of the particles and the adsorbed DNA molecule numbers were calculated by considering the interaction model between the particles and the DNA. The 10- $\mu$ g samples of the $10-\mathrm{nm}$ and 80 -nm PAMAM-modified particles contained $1.7 \times 10^{12}$ particles and $3.4 \times 10^{9}$ particles, respectively. The following numerical values were used for the calculations: single particle volumes of $5.2 \times 10^{2} \mathrm{~nm}^{3}$ and $2.7 \times 10^{5} \mathrm{~nm}^{3}$ from spherical modes for the $10-\mathrm{nm}$ and $80-\mathrm{nm}$ particles, respectively; a $0.84-\mathrm{nm}$ lattice constant for $\mathrm{Fe}_{3} \mathrm{O}_{4}$; and a unit lattice volume of $0.28 \mathrm{~nm}^{3}$. The molecular numbers of the adsorbed $\lambda$ DNA (48502 bp) on the $10-\mathrm{nm}$ particles and $80-\mathrm{nm}$ particles were $1.1 \times 10^{10}$ and $2.7 \times 10^{9}$, respectively. Because the total specific surface area of the $10-\mathrm{nm}$ particles was larger than that of the $80-\mathrm{nm}$ particles of the same weight, the DNA-adsorption capacity of the $10-\mathrm{nm}$ particles was larger than that of the $80-\mathrm{nm}$ particles. However, the amine number that could interact with the phosphate group of the DNA on the single 10-nm particle was less than that for the single $80-\mathrm{nm}$ particle. The 80 -nm single PAMAM-MNP possesses $4.1 \times 10^{4}$ amino groups, whereas the $10-\mathrm{nm}$ single PAMAM-SpMNP possesses $5.2 \times 10^{2}$ amino groups. Thus, the binding interaction of the DNA molecule with the single PAMAM-SpMNP was weaker than that with the single PAMAM-MNPs. The reduced binding interaction from the localized area of individual particles resulted in highly efficient DNA release from the PAMAM-SpMNPs. The dispersivity of the PAMAM-SpMNPs may have also contributed to the high efficiency of the DNA release. In the previous study, we revealed that the release of DNA from amine-modified MNPs occurred by replacing the phosphate groups of the DNA with the phosphate ions in the buffer. ${ }^{20}$ The replacement reaction was promoted by the easy attack of phosphate ions in low agglomeration. We have reported in our previous studies that the use of AEEA-modified MNPs with 1.1 amino groups $\mathrm{nm}^{-2}$ results in a DNA-release efficiency of $85 \%$, whereas the use of the PAMAM-MNPs with 2.0 amino groups $\mathrm{nm}^{-2}$ had an efficiency of $80 \% .{ }^{19}$ Another research group reported the release of $65 \%$ of DNA from cationic poly(lactide) nanoparticles. ${ }^{24}$ In contrast, by optimizing the amino-group density on the $10-\mathrm{nm}$ PAMAM-SpMNPs, we achieved a highly efficient DNA release of greater than $95 \%$ from the surface in this study.

The PAMAM-SpMNPs used in combination with an AMF enabled the acceleration of the DNA recovery. The temperature near the SpMNP surface appeared to rise to $80^{\circ} \mathrm{C}$ or higher; however, the temperature of the suspension remained nearly constant. Several research groups have proposed using various DNA carriers such as gold nanoparticles, ${ }^{25-27}$ polyglycolic acid particles, ${ }^{24,28}$ or liposomes. ${ }^{29}$ The application of these DNA carriers is expected to control the timing of the DNA release and result in little injury to cells. When PAMAM-SpMNPs are used in conjunction with an AMF for gene transfection, the DNA release can be controlled without cell death.

In this study, PAMAM-modified SpMNPs were developed for efficient DNA release. The PAMAM-SpMNPs permitted highly efficient DNA recovery. Furthermore, the DNA recovery using the PAMAM-SpMNPs was accelerated by applying an AMF without a change in temperature. Thus, by enabling control of the DNA release timing, the proposed method for DNA recovery could expand the range of applications to include rapid bacterial testing, gene transfection and the detection of genetically modified organisms. 


\section{ACKNOWLEDGEMENTS}

This work was partially supported by a Grant-in-Aid for Scientific Research (No. 22107009) on the Innovative Areas: 'Fusion Materials' (Area No. 2206) from the Ministry of Education, Culture, Sports, Science and Technology (MEXT) and a Grant-in-Aid for challenging Exploratory Research (No. 22651046) from the Japan Society for the Promotion of Science (JSPS).

1 Boom, R., Sol, C. J., Salimans, M. M., Jansen, C. L., Wertheim-van Dillen, P. M. \& van der Noordaa, J. Rapid and simple method for purification of nucleic acids. J. Clin. Microbiol. 28, 495-503 (1990).

2 McCloskey, K. E., Chalmers, J. J. \& Zborowski, M. Magnetic cell separation: characterization of magnetophoretic mobility. Anal. Chem. 75, 6868-6874 (2003).

3 Matsunaga, T., Takahashi, M., Yoshino, T., Kuhara, M. \& Takeyama, H. Magnetic separation of $\mathrm{CD} 14+$ cells using antibody binding with protein A expressed on bacterial magnetic particles for generating dendritic cells. Biochem. Biophys. Res. Commun. 350, 1019-1025 (2006)

4 Kuhara, M., Takeyama, H., Tanaka, T. \& Matsunaga, T. Magnetic cell separation using antibody binding with protein a expressed on bacterial magnetic particles. Anal. Chem. 76, 6207-6213 (2004).

5 Alefantis, T., Grewal, P., Ashton, J., Khan, A. S., Valdes, J. J. \& Del Vecchio, V. G. $A$ rapid and sensitive magnetic bead-based immunoassay for the detection of staphylococcal enterotoxin B for high-through-put screening. Mol. Cell. Probes. 18, 379-382 (2004).

6 Tanaka, T., Takeda, H., Ueki, F., Obata, K., Tajima, H., Takeyama, H., Goda, Y., Fujimoto, S. \& Matsunaga, T. Rapid and sensitive detection of 17 beta-estradiol in environmental water using automated immunoassay system with bacterial magnetic particles. J. Biotechnol. 108, 153-159 (2004).

7 Tanaka, T. \& Matsunaga, T. Detection of $\mathrm{HbA}(1 \mathrm{c})$ by boronate affinity immunoassay using bacterial magnetic particles. Biosens. Bioelectron. 16, 1089-1094 (2001)

8 Maruyama, K., Takeyama, H., Nemoto, E., Tanaka, T., Yoda, K. \& Matsunaga, T. Single nucleotide polymorphism detection in aldehyde dehydrogenase 2 (ALDH2) gene using bacterial magnetic particles based on dissociation curve analysis. Biotechnol. Bioeng. 87, 687-694 (2004)

9 Martins, S. A., Prazeres, D. M., Fonseca, L. P. \& Monteiro, G. A. Application of central composite design for DNA hybridization onto magnetic microparticles. Anal. Biochem. 391, 17-23 (2009).

10 Matsunaga, T., Maruyama, K., Takeyama, H. \& Katoh, T. High-throughput SNP detection using nano-scale engineered biomagnetite. Biosens. Bioelectron. 22, 2315-2321 (2007).

11 Maruyama, K., Takeyama, H., Mori, T., Ohshima, K., Ogura, S., Mochizuki, T. \& Matsunaga, T. Detection of epidermal growth factor receptor (EGFR) mutations in nonsmall cell lung cancer (NSCLC) using a fully automated system with a nano-scale engineered biomagnetite. Biosens. Bioelectron. 22, 2282-2288 (2007).

12 Nakagawa, T., Maruyama, K., Takeyama, H. \& Matsunaga, T. Determination of microsatellite repeats in the human thyroid peroxidase (TPOX) gene using an automated gene analysis system with nanoscale engineered biomagnetite. Biosens. Bioelectron. 22, 2276-2281 (2007)

13 Obata, K., Segawa, O., Yakabe, M., Ishida, Y., Kuroita, T., Ikeda, K., Kawakami, B. Kawamura, Y., Yohda, M., Matsunaga, T. \& Tajima, H. Development of a novel method for operating magnetic particles, Magtration Technology, and its use for automating nucleic acid purification. J. Biosci. Bioeng. 91, 500-503 (2001).

14 Nakagawa, T., Hashimoto, R., Maruyama, K., Tanaka, T., Takeyama, H. \& Matsunaga, T. Capture and release of DNA using aminosilane-modified bacterial magnetic particles for automated detection system of single nucleotide polymorphisms. Biotechnol. Bioeng. 94, 862-868 (2006).

15 Yoza, B., Arakaki, A., Maruyama, K., Takeyama, H. \& Matsunaga, T. Fully automated DNA extraction from blood using magnetic particles modified with a hyperbranched polyamidoamine dendrimer. J. Biosci. Bioeng. 95, 21-26 (2003).

16 Yoza, B., Arakaki, A. \& Matsunaga, T. DNA extraction using bacterial magnetic particles modified with hyperbranched polyamidoamine dendrimer. J. Biotechnol. 101, 219-228 (2003).

17 Yoza, B., Matsumoto, M. \& Matsunaga, T. DNA extraction using modified bacterial magnetic particles in the presence of amino silane compound. J. Biotechnol. 94, 217-224 (2002)

18 Ota, H., Lim, T. K., Tanaka, T., Yoshino, T., Harada, M. \& Matsunaga, T. Automated DNA extraction from genetically modified maize using aminosilane-modified bacterial magnetic particles. J. Biotechnol. 125, 361-368 (2006).

19 Tanaka, T., Sakai, R., Kobayashi, R., Hatakeyama, K. \& Matsunaga, T. Contributions of phosphate to DNA adsorption/desorption behaviors on aminosilane-modified magnetic nanoparticles. Langmuir 25, 2956-2961 (2009).

20 Tanaka, T., Shibata, K., Hosokawa, M., Hatakeyama, K., Gomyo, H., Arakaki, A., Mogi, T., Taguchi, T., Wake, H., Tanaami, T. \& Matsunaga, T. Characterization of magnetic nanoparticles modified with thiol core, functionalized PAMAM dendron for DNA recovery. J. Colloid Interface Sci. in press (2012).

21 de Chatel, P. F., Nandori, I., Hakl, J., Meszaros, S. \& Vad, K. Magnetic particle hyperthermia: Neel relaxation in magnetic nanoparticles under circularly polarized field. J. Phys. Condens. Matter 21, 124202 (2009).

22 Matsumoto, M. Yoshimura, N., Honda, Y, Hiraoka, M. \& Ohura, K. Ferromagnetic hyperthermia in rabbit eyes using a new glass-ceramic thermoseed. Graefes. Arch. Clin. Exp. Ophthalmol. 232, 176-181 (1994)

23 Wen, J., Guillo, C., Ferrance, J. P. \& Landers, J. P. DNA extraction using a tetramethy orthosilicate-grafted photopolymerized monolithic solid phase. Anal. Chem. 78, 1673-1681 (2006).

24 Munier, S., Messai, I., Delair, T, Verrier, B, \& Ataman-Onal, Y Cationic PLA nanoparticles for DNA delivery: comparison of three surface polycations for DNA binding, protection and transfection properties. Colloids Surf. B Biointerfaces 43, 163-173 (2005)

25 Hussain, N., Singh, B., Sakthivel, T. \& Florence, A. T. Formulation and stability of surface-tethered DNA-gold-dendron nanoparticles. Int. J. Pharm. 254, 27-31 (2003).

26 Poon, L., Zandberg, W., Hsiao, D., Erno, Z., Sen, D., Gates, B. D. \& Branda, N. R. Photothermal release of single-stranded DNA from the surface of gold nanoparticles through controlled denaturating and Au-S bond breaking. ACS Nano. 4, 6395-6403 (2010).

27 Singh, B., Hussain, N., Sakthivel, T. \& Florence, A. T. Effect of physiological media on the stability of surface-adsorbed DNA-dendron-gold nanoparticles. J. Pharm. Pharmacol. 55, 1635-1640 (2003).

28 Ribeiro, S., Hussain, N. \& Florence, A. T. Release of DNA from dendriplexes encapsulated in PLGA nanoparticles. Int. J. Pharm. 298, 354-360 (2005).

29 Perrie, Y., Barralet, J. E., McNeil, S. \& Vangala, A. Surfactant vesicle-mediated delivery of DNA vaccines via the subcutaneous route. Int. J. Pharm. 284, 31-41 (2004).

Supplementary Information accompanies the paper on Polymer Journal website (http://www.nature.com/pj) 